\title{
Implementing a model for identifying organizational complications for the purpose of increasing productivity in hydropower plant
}

\author{
Seyede Zahra Erfani ${ }^{1}$, Seyed Masood Taghvaee ${ }^{1}$, Farbod Estiri ${ }^{1}$, Farzad Ramin ${ }^{2}$ \\ (1. Department of Hydropower Plants, Iran Water Resources Management Company, Tehran 1415855641, Iran; \\ 2. Department of Mobile, Telecommunication Company, Zahedan, Iran)
}

\begin{abstract}
The present economical conditions on today's world require specific point of view and policy making in business agencies. In this competitive world to achieve competence, competitive advantages in order to better governance, organizations have to increase their competitive powers through promotion and productivity. One of the fundamental approaches to elevate the productivity level is finding the complications and obstacles, and arise planning to remove them. In order to understand organizational complication, we have tried to take critical factors of success and continue improvement into consideration to demonstrate a model to find the main and radical problems and complications and recognize the recoverable areas in the business agencies. In order to verify and validate the performed research, he planned model has been accomplished in the Hydropower Plant Department, positive and acceptable results were obtained and organizations total factor productivity improvement was achieved which was appreciated by the organization.
\end{abstract}

Key words: productivity; critical factors of success; continues improvement; organizational complication; hydropower plant

\section{Introduction}

Increasing productivity level is ultimately the key to survival of any organization which leads to high governance and prosperousness, thus systematic complication detection and recognition of internal and external problems is of great importance. Therefore, the need for using a very simple model, which is usable by economic agencies, is one of momentous affair.

In Iran like the other countries, energy plays an important role in the economic expansion which has a direct link to the economy expansion of country. Since hydropower energy is permanent and clean energy, paying attention to the processes which increase the productivity level in hydropower plant in order to increase the governance of hydropower plant in the energy market is important. The aim of this article is demonstrating a model with focus on searching for insight acquisition by taking advantage of Deming cycle and vital attitude to critical factors of success. The authors implement the model in hydropower plant which is a sample of business

\footnotetext{
Seyede Zahra Erfani, M.Sc., planning and project control engineer, Department of Hydropower Plants, Iran Water Resources Management Company; research fields: industrial engineering and optimization.

Seyed Masood Taghvaee, Ph.D., assistant director, Department of Hydropower Plants, Iran Water Resources Management Company; research field: mechanic engineering.

Farbod Estiri, B. S., operation and optimization manager, Department of Hydropower Plants, Iran Water Resources Management Company; research fields: hydro power plant engineering and optimization.

Farzad Ramin, B. S., mobile telecommunication manager, Department of Mobile, Telecommunication Company; research fields: optimization models and organizational complications models in different industries.
} 
and economical agency.

\section{Literature review}

\subsection{Hydropower plants}

Hydropower plant is a power plant that uses moving water to a turbine generator to produce electricity (www.energy.gov).

\subsection{Critical success factor}

Factors in the organization, which failure to access them will make it impossible to achieve the organization goals.

\subsection{Continuous improvement process (CIP or CI)}

CIP is an ongoing effort to improve products, services or processes. These efforts can seek "incremental" improvement over time or "breakthrough" improvement all at once.

\subsection{Deming cycle: The wheel of continuous improvement}

A model (made popular by Edwards Deming) describes an iterative process designed to drive continuous improvement.

\subsection{Productivity}

Productivity is a measure of output from a production process, per unit of input.

\section{Proposed model}

The authors demonstrate the model for detecting complications in the hydropower plant which is an economic agency in order to increase the productivity level and as well achieving high governance in the energy market. Regarding the stated weak points of the complication-detecting methodologies, also with respect to the existing positive points in the methodologies (Wiley Chichester, 1999), this model consists of initiation, planning, executing, monitoring, controlling and lessons learned phases. These phases clearly depict continuous improvement. The proposed model lessons learned phase is documentation of results and compiling lessons learned for future applications.

The authors were benefited from Deming cycle which describes an iterative process designed to drive continuous improvement.

The authors had a glance on project management models, the model has initiating and lesson learnt phase similar to project management models. The proposed model is shown in Fig. 1.

\subsection{Initiating phase}

Procuring the top manager support;

Resource devotion (budget, place, facilities);

Explanation about the premium of governance, productivity, organizational complication.

\subsection{Planning phase}

\subsubsection{Team establishment}

In this stage, after instruction of the concepts of the mission and the goal, all the people are requested to write down the mission and the goal of the company and convert it into a united mission and goal in a teamwork frame then the teams will discuss with one another and prepare a common mission and goal for the company. 
Implementing a model for identifying organizational complications for the purpose of increasing productivity in hydropower plant

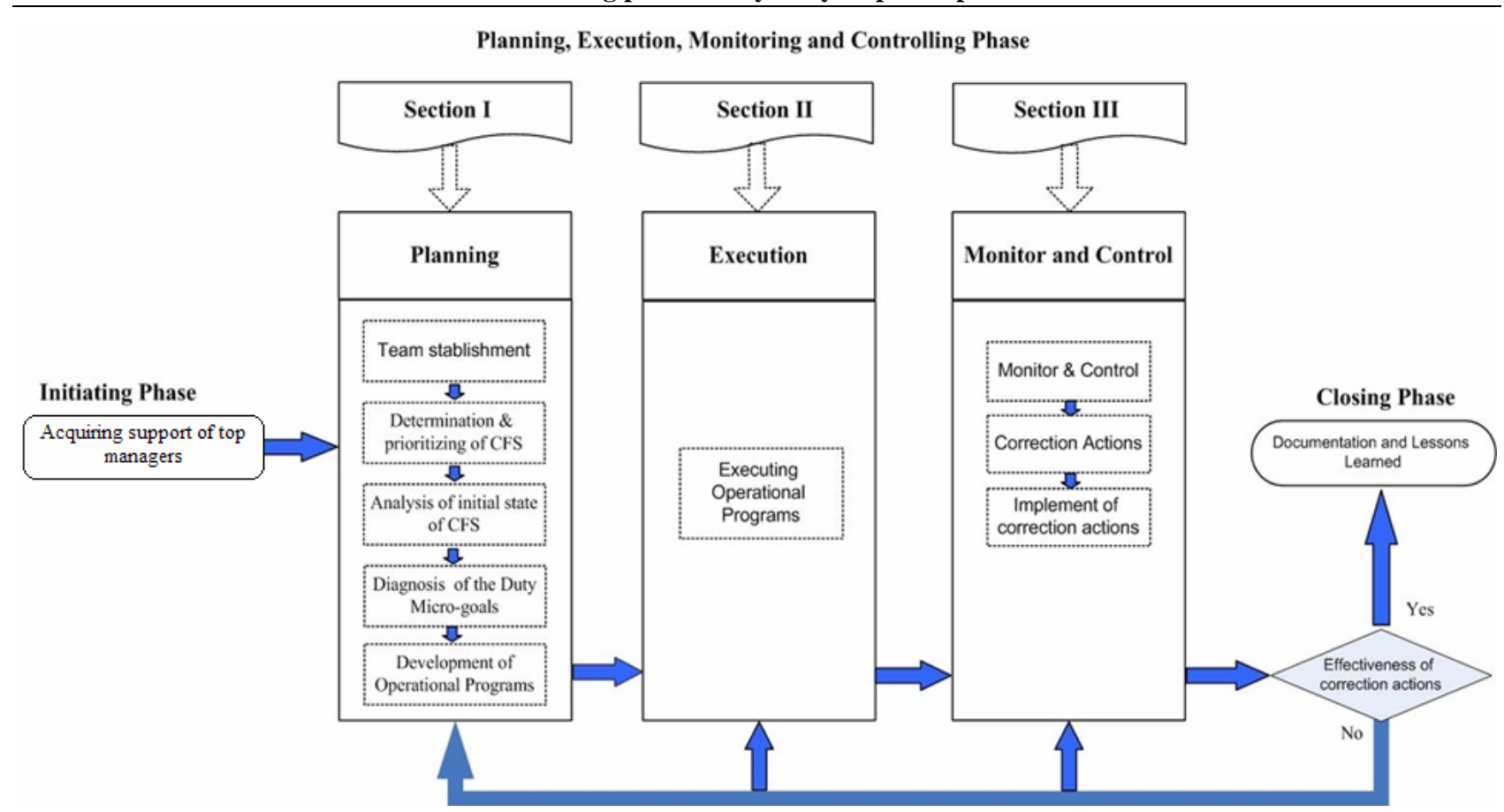

Fig. 1 The proposed model with considering continuous improvement

\subsubsection{Determination and prioritizing of critical factors of success}

In this stage, after instructing the concepts of the critical factors of success, all the members are requested to discuss the critical factors of success of the organization (factors, areas, activities, ... in the organization, which failure to access them will make it impossible for the organization to realize its mission) in an individual and then team work. And then, the teams by discussing and exchanging their views will reach some critical factors of success. The critical factors of success will be prioritized by Multi-Attribute Group Decision Making (MAGDM) techniques.

3.2.3 Determination and prioritizing of each CSFs complication

In this stage, regarding the offered instruction, the teams determine the complications of each CSF (they are complications of internal and external factors, which make the access to the CSF difficult or impossible). These complications are also prioritized in a final teamwork frame and by help of AHP or any other approach that the facilitator team deems favors.

\subsubsection{Determination of approaches of macro-goal setting}

In this stage, complication detectors analyze the obtained results in a team frames; SWOT matrix may be a proper technique, especially when ability-makers of each CSF have been recognized. Regarding the performed analyses, the approaches and goal-setting for resolving the complications are performed. And then, the teams will reach a uniform approaches and goals by discussing and exchanging views.

As organizations are usually in short of resources, and resolving complication is not an exception, and that organizations usually are able to execute only limited approaches at the same time, by the help of using related mathematical models like DEMATEL, and regarding mutual effects of approaches, the Road Map is prepared.

\subsubsection{Determination of the duty micro-goals}

In this stage, the participating members in the process of complication detection interpret the approaches and the goals of resolving the complications in their own units in duty-team frames, and then in order to correspondence 
of these approaches and goals, they seek the approval of all teams by discussing and exchanging of views, and in fact the approaches and goals of resolving the complications (individual/duty) is confirmed and attested.

\subsubsection{Preparation of operational programs}

As the approaches are stated in general sentences and the details of execution is not considered, therefore, duty-teams prepare operational programs related to approaches, and they seek the approval of all the operational programs by all members of the teams. It is necessary to determine the control indexes for preparation of operational programs. Also, emphasis on teamwork for performing the programs in preparation of operational programs is essential.

\subsection{Execution}

In this stage, regarding defined priorities (Road Map), the prepared operational programs are performed and are controlled and reviewed by the help of predetermined indices.

\subsection{Monitor and control}

The authors designed our model by the purpose of continues improvement; in this stage we evaluate the impact of our model on the costumer, employee, society, key process and productivity indexes. If the results are not successful, the authors reform each stage which is necessary. Once all this stages are completed to the fullest satisfaction, the improvement is standardized. The standardized work or product is the result of improvement initiative but it is not stopped here. With the changing circumstances or new techniques this standardized work, process, product or service is again subjected to further improvement thus repeating the Deming cycle again and again (see Fig. 2).

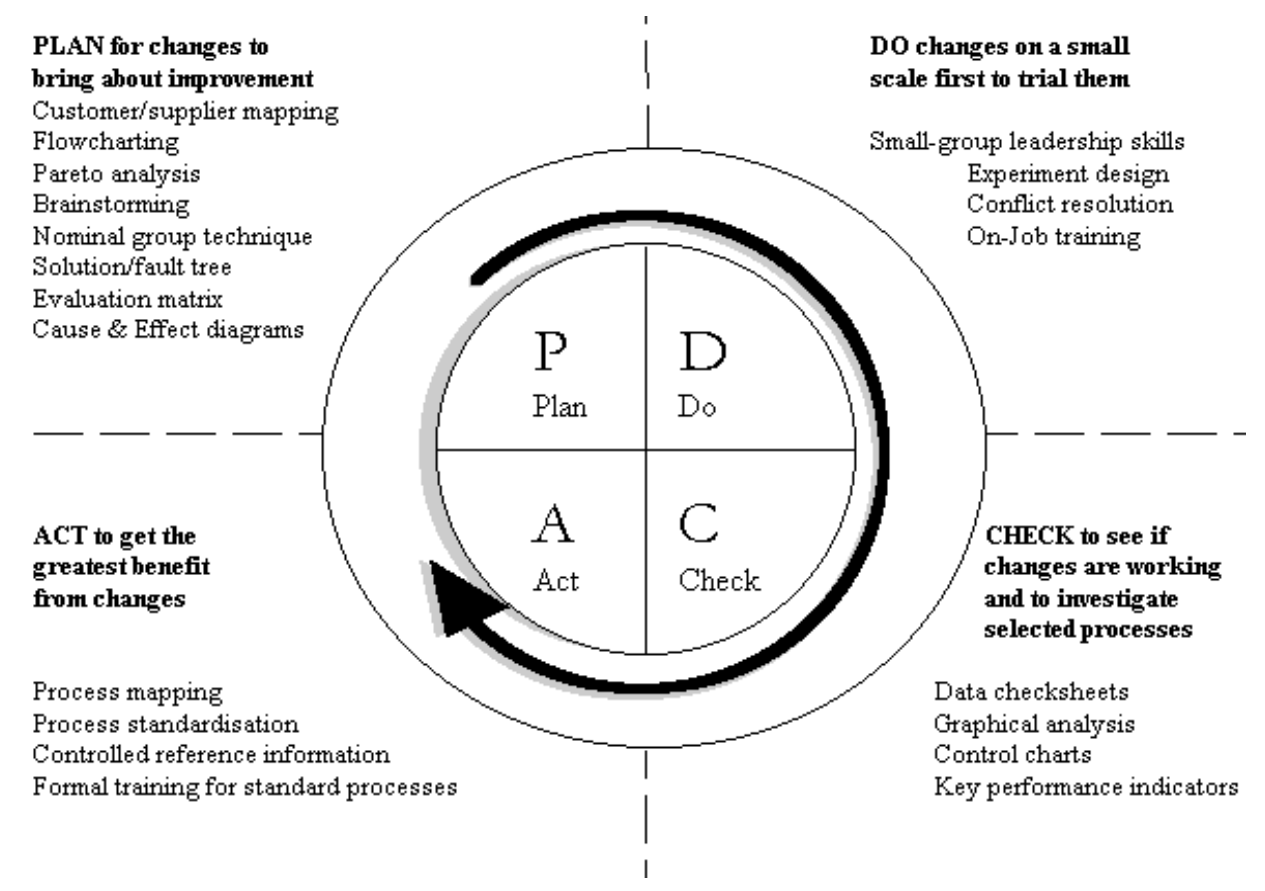

Fig. 2 The Deming cycle

Data source: http://www.sqaki.com/Deming/

\subsection{Closing phase}

The team documents the result and experience for the organizational generation. 


\section{Application of our proposed model}

\subsection{Initiating phase}

\subsubsection{Acquiring the top manager support}

The top manager of the department of hydropower plants was eager to improve the productivity and energy generation in the hydropower plants. He was persuaded that identifying complication is vital. Hence the essential facilities were prepared (place, budget, people ...).

\subsubsection{A brief history of hydropower plant department}

The role of the of hydropower plants is to conduct research and development (R\&D) programs that will improve the technical, societal and environmental benefits of hydropower and provide cost competitive technologies and approaches that enable the development of new and incremental hydropower capacity which will result in increasing the clean energy that has an important role in the expansion of economy of the Iran (www.hydropower.id.doe).

\subsection{Planning phase}

\subsubsection{Organizing work team}

Work teams consisting of different specialties consisting of 3 up to 6 people and in cross-functional form were developed. They prepared vision statement and mission statement of hydropower plants.

(1) Vision statement of the hydropower plant

The vision of hydropower plant is producing clean energy and finding the highest governance in the energy market.

(2) Mission statement of the hydropower plant

Hydropower plant organization acts as the most precedent plant in the producing energy. In order to provide advantages for producing clean and permanent energy, this organization concentrates on management and human resource development, resource improvement based on customer leadership, environmental biology standard consideration, appropriate technology utilization and making benefit of the organization's human specialist power.

\subsubsection{Determination of CSFs (Critical Area Recognition)}

The team members determined the success critical factors of hydropower plant in order to reach the organization's mission and vision, then they tried to prioritize CSFs, storytelling, expressing experience was of great importance (Clandinin, 2003). MAGDM techniques and AHP (the Analytical Hierarchy Process) were used. The measured CI was 0.051 that was completely correct and accurate. According to the measured weights in AHP, 4 of the CSFs that had the maximum weight attained $90 \%$ of the weights and were chosen as the company's critical success factors.

Final critical success factors:

- Physical Asset Management.

- Human Resource Development and Organizational Culture Improvement.

- Corporate planning management.

- Technology management.

- Financial management.

- Implementing knowledge management.

4.2.3 Determination and prioritizing of complication critical factors of success

Team members found the complication for every CSF then all the team discussed the matter together. The 
other staff were asked to take participate by filling the questioner and asking them question. All the people who had suggestion in this order some were rewarded (Ajzen, 1999). At first the problems were 20 but after team discussion all the team agreed on 5 of them. These 5 problems were prioritized by help of AHP. Here there are examples for Problems of Management and Human Resource Development and Organizational Culture Improvement and knowledge management:

4.2.3.1 Physical asset management

(1) Inappropriate organizational structure;

(2) Lack of professional staff;

(3) Lack of appropriate technique for maintenance;

(4) Lack of guide direction for equipments.

4.2.3.2 Human resource development and organizational culture improvement

(1) Poor performance appraisal system;

(2) Inappropriate organizational structure and inflexibility;

(3) Organizational culture weakness;

(4) Human resource planning weakness.

4.2.3.3 Knowledge management

(1) Knowledge was created but it wasn't the precious knowledge for energy industry;

(2) Knowledge was lost by staff movement and staff retirement;

(3) Knowledge was not stored so that is accessible for all the staff (it was kept in the personal files);

(4) Knowledge was not transferred among the staff;

(5) The knowledge sources includes the knowledgeable staff and documents were not identified;

(6) Repetitive task and fault was done in different section of the office.

\subsubsection{Determination and prioritizing of macro goals}

Determining the corporate solutions and the long term objectives. By using analytical methods as SWOT, team member presented 8 corporate solutions in order to eliminate the company's problems and chose 5 corporate objectives for the company. The obtained Road Map was obtained with DEMATEL technique and direct and indirect effects of each solution on each other.

(1) Physical asset management improvement;

(2) Human resource management improvement;

(3) Planning management improvement;

(4) Procurement management improvement;

(5) Quality management improvement;

(6) Financial management improvement;

(7) Implementing knowledge management;

(8) Cost leadership management.

\subsection{Executing phase}

As lack of physical asset management was one of the complications, so we took in mind to execute some maintenance courses and finding the best technique (Avison \& Fitzgerald, 2001), we took advantage of the hydropower expert this case. Some fundamental method was taken into consideration.

In the same time as knowledge is the key of success for all organization (Al-Hawamdeh, 2003), the qualitative and quantitative research was done by Punch (2005). The authors used the Knowledge management 
Implementing a model for identifying organizational complications for the purpose of increasing productivity in hydropower plant

implementation models in order to create, organize, share and utilize the necessary knowledge for improving the maintenance technique. Some expert was employed and all duties were done in the groups.

\subsection{Monitor and control}

The impact of model was measured on productivity indexes like: costumer, society satisfaction, key process like: profit productivity, increasing of generated energy, capital, the share of stockholder, growth in all of them was observed. As well we had increase in labour cost competitive index, process efficiency index, knowledge management practice as we can see in Fig. 3, Fig. 4 and Fig. 5.

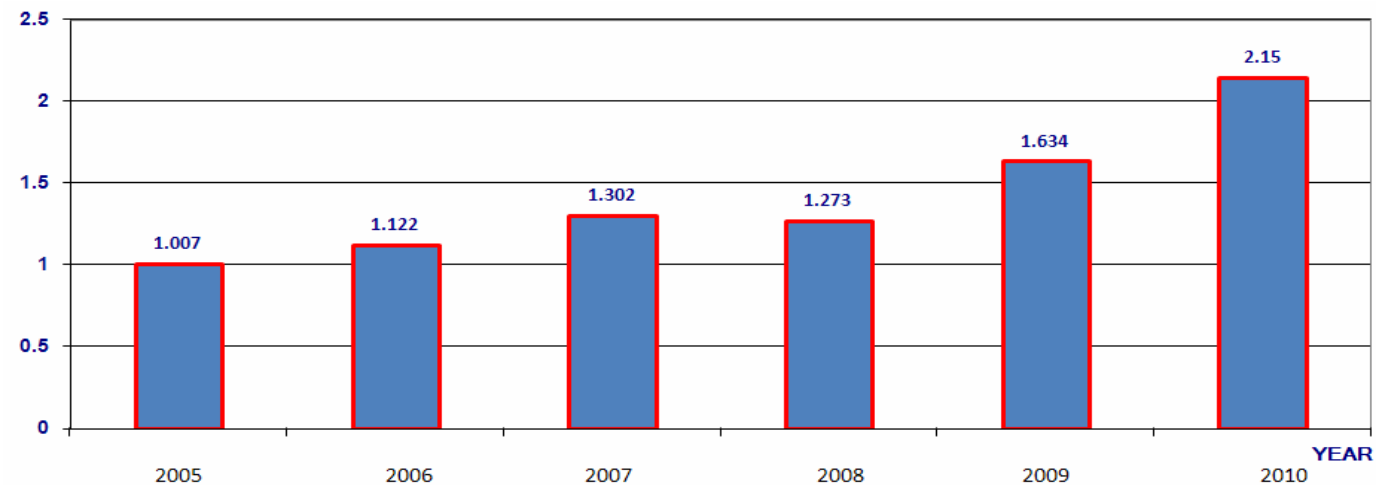

Fig. 3 Labour cost competitive index of hydropower plant

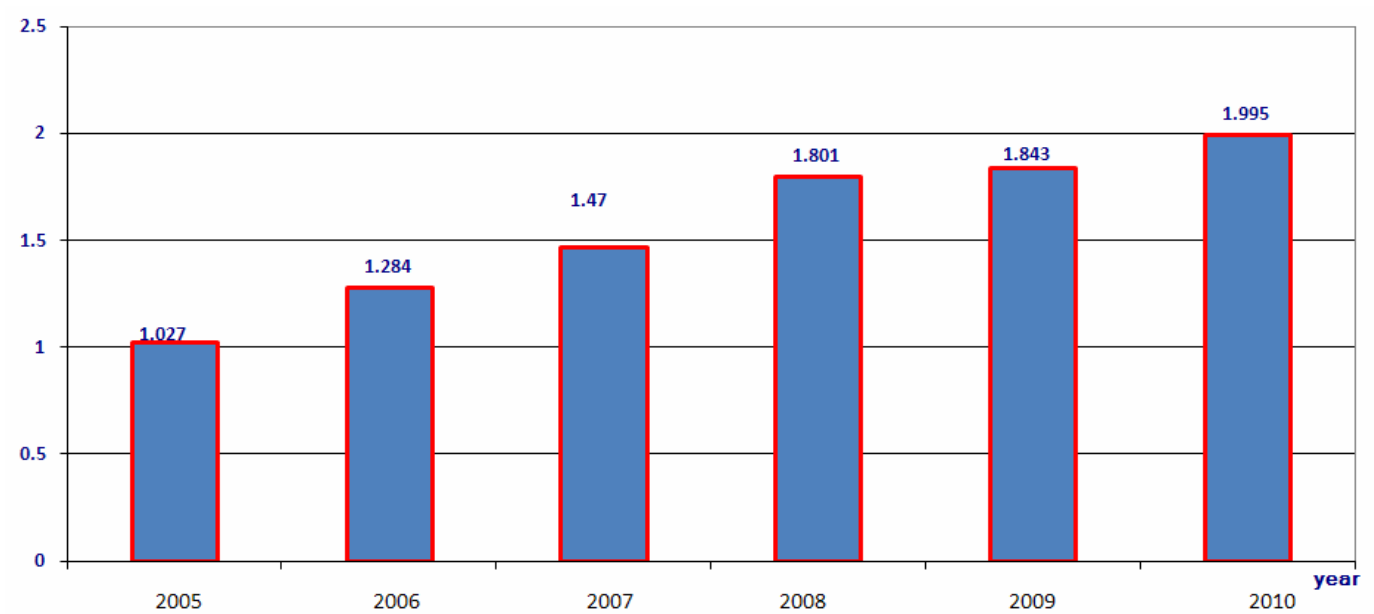

Fig. 4 Process efficiency index of hydropower plant

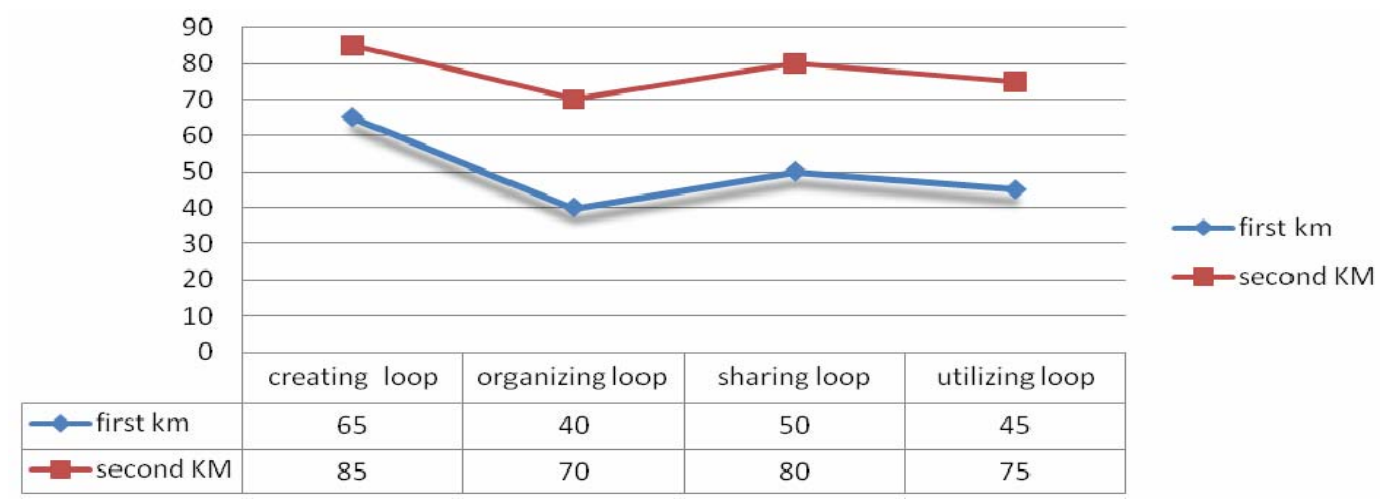

Fig. 5 KM practice outcome before and after applying proposed model 
The team document the result and experience for the next project and use knowledge asset in services and product.

\section{Conclusion}

This model consists of certain steps that can be used to resolve all problems of organizations from various levels and goals by offering a way of thinking in order to diagnose the problems of the organization that prevent it to reach the mission and excellence, the model creation was by taking advantage of Deming cycle and project management model by the purpose of continuous improvement, since productivity is a key to improve the governance by this model which is a way of capturing the essence of problems we were able to define the organizational complication and offer improvement solutions.

This model includes four basic phases. These phases are the initial phase, planning, execution, monitor and control and lesson learned phase. This model which considers finding the complications and obstacles, according to CSF and continues improvement resulted in improvement of productivity index, customer satisfaction, society satisfaction, employee satisfaction, key performance that can lead to high governance.

\section{References:}

Ajzen, I.. (1991). The theory of planned behaviour. Organizational Behaviour and Human Decision Processes, 50(2), $179-211$.

Al-Hawamdeh, S.. (2003). Knowledge management: Cultivating knowledge professionals. Oxford: Chandos Publishing.

Avison, D. \& Fitzgerald, G.. (2001). Information systems development: Methodologies, techniques and tools. Maidenhead, UK: McGraw Hill.

Checkland, P. B. \& Scholes, J.. (1999). Soft system methodology in action. Chichester: Wiley.

Clandinin, D. J. \& Connelly, F. M.. (2000). Narrative inquiry experience and story in qualitative research. San Francisco: JosseyBass Publishers.

Drucker, P.. (1995). The post-capitalist society. Oxford: ButterworthHeineman.

Punch, K. F.. (2005). Introduction to social research quantitative and qualitative approaches (2nd ed.). London: SAGE Publications.

(Edited by Ruby and Chris) 